\title{
Interstitial glycerol as a marker for membrane phospholipid degradation in the acutely injured human brain
}

\author{
Lars Hillered, Johann Valtysson, Per Enblad, Lennart Persson
}

\begin{abstract}
Objective- Brain interstitial glycerol was studied as a potential marker for membrane phospholipid degradation in acute human brain injury.

Methods-Glycerol was measured in microdialysis samples from the frontal lobe cortex in four patients in the neurointensive care unit, during the acute phase after severe aneurysmal subarachnoid haemorrhage. Microdialysis probes were inserted in conjunction with a ventriculostomy used for routine intracranial pressure monitoring. Clinical events involving hypoxia/ischaemia were diagnosed by neurological signs, neuroimaging (CT and PET), and neurochemical changes of the dialysate-for example, lactate/pyruvate ratios and hypoxanthine concentrations.

Results-Altogether 1554 chemical analyses on 518 microdialysis samples were performed. Clinical events involving secondary hypoxia/ischaemia were generally associated with pronounced increases (up to 15-fold) of the dialysate glycerol concentration. In a patient with a stable condition and no signs of secondary hypoxia/ischaemia the glycerol concentration remained low. Simultaneous determination of glycerol in arterial plasma samples showed that the changes in brain interstitial glycerol could not be attributed to systemic changes and an injured blood brain barrier.
\end{abstract}

Conclusions-This study suggests that membrane phospholipid degradation occurs in human cerebral ischaemia. Interstitial glycerol harvested by microdialysis seems to be a promising tool for monitoring of membrane lipolysis in acute brain injury. The marker may be useful for studies on cell membrane injury mechanisms mediated by for example, $\mathrm{Ca}^{2+}$ disturbances, excitatory amino acids, and reactive oxygen species; and in the evaluation of new neuroprotective therapeutic strategies.

(F Neurol Neurosurg Psychiatry 1998;64:486-491)

Keywords: human cerebral ischaemia; interstitial glycerol; membrane phospholipid degradation; oxygen radicals

Degradation of membrane phospholipids is a well known phenomenon in acute experimental brain injury and is thought to underlie the disruption of cellular membranes with loss of vital functions such as barrier and transport capabilities, leading to a cascade of harmful events including oedema formation. ${ }^{1-6}$ Such increased lipolytic activity has mainly been studied by measuring free fatty acids and membrane phospholipids extracted from brain homogenate samples in animal models of ischaemia, hypoxia, hypoglycaemia, and epilepsy. ${ }^{4}$ To our knowledge there is little or no information on membrane phospholipid degradation in acute human brain injury. Glycerol is an end product of membrane phospholipid degradation and has been used to study membrane phospholipid degradation in brain homogenates after cerebral ischaemia and seizures. ${ }^{7-9}$ In a recent study on traumatic brain injury in rats, interstitial glycerol harvested by intracerebral microdialysis was found to be a promising marker for the monitoring of post-traumatic membrane phospholipid degradation. ${ }^{10}{ }^{11}$ We have developed the microdialysis technique for neurochemical monitoring in patients with severe acute brain injuries, including subarachnoid haemorrhage and trauma. ${ }^{12-15}$ This has created a new opportunity for neurochemical monitoring of the human brain. The present study tested the hypothesis that interstitial glycerol is a useful marker for monitoring of membrane phospholipid degradation in acute human brain injury. Some of the results have appeared in abstract form. ${ }^{16}$

\section{Patients and methods}

Four patients were studied during the acute phase after serious aneurysmal subarachnoid haemorrhage. The patients required an intraventricular catheter for intracranial pressure monitoring and were treated at the neurointensive care unit. The clinical management was based on early aneurysm surgery and "aggressive" neurointensive care. Intracerebral microdialysis was performed as described in detail elsewhere. ${ }^{13}$ In short, a microdialysis probe (CMA/10, $4 \mathrm{~mm}$ polyamide membrane, CMA/ Microdialysis, Stockholm, Sweden) was inserted in the frontal cortex in conjunction with a ventriculostomy. The probe was perfused with sterile artificial CSF (containing $140 \mathrm{mM}$ $\mathrm{Na}^{+}, 2.7 \mathrm{mM} \mathrm{K}^{+}, 1.2 \mathrm{mM} \mathrm{Ca}{ }^{2+}, 0.9 \mathrm{mM} \mathrm{Mg}{ }^{2+}$, and $147 \mathrm{mmol} \mathrm{Cl}^{-}$) at a rate of $2 \mu \mathrm{l} / \mathrm{min}$ using a CMA/100 microinjection pump (CMA/ Microdialysis). An equilibration period of 30 to 60 minutes without sampling was allowed after probe implantation or resumed pumping after accidental interruptions or changing syringes. ${ }^{12}$ Dialysate was collected on a 24 hour/day basis, normally in 60 minute fractions, during seven 
Table 1 Patient characteristics

\begin{tabular}{llllllll}
\hline $\begin{array}{l}\text { Case } \\
\text { No }\end{array}$ & $\begin{array}{l}\text { Hand Hon } \\
\text { admission }\end{array}$ & $\begin{array}{l}\text { CT Fisher } \\
\text { grade }\end{array}$ & $\begin{array}{l}\text { Aneurysm } \\
\text { location }\end{array}$ & $\begin{array}{l}\text { MD probe } \\
\text { location }\end{array}$ & MD days & $\begin{array}{l}\text { Aneurysm } \\
\text { surgery day }\end{array}$ & $\begin{array}{l}\text { GOS } \\
\text { 3 months }\end{array}$ \\
\hline 1 & IV & 4 & ACoA & R frontal & $1-9$ & 3 & SD \\
2 & II & 2 & L MCA & R frontal & $1-9$ & 3 & SD \\
3 & III & 4 & ACoA & R frontal & $2-10$ & 3 & MoD \\
4 & II & 4 & R ICA & L frontal & $2-8$ & 3 & GR \\
\hline
\end{tabular}

$\mathrm{H}$ and $\mathrm{H}=\mathrm{Hunt}$ and Hess; $\mathrm{CT}=$ computerised tomography; $\mathrm{AcoA}=$ anterior communicating artery; $\mathrm{MCA}=$ middle cerebral artery; $\mathrm{ICA}=$ internal carotid; $\mathrm{R} / \mathrm{L}=$ right/left hemisphere; $\mathrm{MD}=$ microdialysis; $\mathrm{MD}$ days = duration of microdialysis measurement; GOS = Glasgow outcome scale ( $\mathrm{SD}$, severe disability; $\mathrm{MoD}$, moderate disability; GR, good recovery). For further explanation see text.

to eight days. During the night $(1100 \mathrm{pm}$ to 8 $00 \mathrm{am})$ three hour fractions were sampled. The samples were stored at $-70^{\circ} \mathrm{C}$ until analysis. The study was based on 518 collected samples and 1554 chemical analyses. Glycerol was measured on a CMA/600 microdialysis analyser (CMA/Microdialysis). This is a self calibrating autoanalyser designed for microdialysis samples measuring glycerol enzymatically. ${ }^{17}$ In our hands the within run imprecision (coefficient of variation) was 3\% at the $15 \mu \mathrm{mol} / 1$ concentration $(n=10)$. Lactate and pyruvate were analysed by high performance liquid chromastography with UV detection $(214 \mathrm{~nm})$ as described previously. ${ }^{18}$ Plasma concentrations of glycerol were determined by performing microdialysis (the same membrane length, perfusion medium, and perfusion rate as for brain tissue) on heparinised arterial plasma samples ${ }^{17}$ from the same patients, to allow a direct comparison with the interstitial glycerol concentrations. The dialysate lactate/pyruvate $(\mathrm{L} / \mathrm{P})$ ratio was used as a marker for energy disturbances due to ischaemia, reflecting the redox state of the cells. This ratio is normally $<20^{13} 15$ and probably independent of probe recovery. ${ }^{19}$ The microdialysis results were compared with routine data on the clinical course including neurological status, physiological and chemical monitoring, and neuroimaging (CT and PET). All microdialysis results are presented as dialysate (D) concentrations without correction for microdialysis probe recovery, as there is no suitable method available for continuous or repeated determination of in vivo probe recovery. In vitro recovery was not determined for sterility reasons. In any case, in vitro recovery cannot be used to assess in vivo recovery. ${ }^{20}$ Simple regression analysis was performed to determine the correlations between brain interstitial glycerol and hypoxanthine, glutamate (with data from Persson et $a l^{15}$ ), lactate, and L/P ratio, in all patients (Stat View 4.01, Abacus Concepts Inc, Berkeley, CA, USA). Clinical outcome according to the Glasgow outcome scale (GOS) ${ }^{21}$ was assessed three months after subarachnoid haemorrhage. The protocol was approved by the ethics committee at the Uppsala University Hospital and permission to use microdialysis was obtained by the patient's relatives.

Results

The patients had all had a serious subarachnoid haemorrhage. This was defined as a high Hunt and Hess grade ${ }^{22}$ on admission, early neurological deterioration, and/or a high Fisher grade on $\mathrm{CT}^{23}$ The table shows some clinical characteristics of the patients. In all patients several CT scans and in case 1 also PET (regional cerebral blood flow, cerebral metabolic rate of oxygen, and oxygen extraction ratio) were performed before, during, and after the microdyalisis period. ${ }^{14}$ Microdialysis data on energy related metabolites and excitatory amino acids as well as CT and PET findings in these patients have appeared in previous reports. ${ }^{14} 15$

CASE 1

This patient (a 56 year old woman) developed cerebral ischaemia starting during surgery and this eventually resulted in a cerebral infarct in the probe area. The patient was initially in Hunt and Hess grade IV and Fisher grade 4 . She immediately received an intraventricular catheter (with the attached microdialysis probe) in the right frontal lobe for CSF drainage. She recovered consciousness after CSF drainage and was operated on on day 3. Figure 1 illustrates the entire 188 hour (7.8 days) microdialysis observation period. Before surgery the $\mathrm{D}-\mathrm{L} / \mathrm{P}$ ratio was virtually normal and the D-glycerol concentration was low $(<10$ $\mu \mathrm{mol} / \mathrm{l})$, after an initial increase. The aneurysm ruptured during surgery and both anterior cerebral arteries were temporarily clipped three times. Shortly thereafter the D-L/P ratio increased greatly, reflecting cerebral ischaemia. After repair of the aneurysm and removal of the temporary clips, a partial restitution of energy metabolism was seen as indicated by a decreasing trend for the D-L/P ratio. However, a few hours later a secondary deterioration was seen with a dramatic increase of the $\mathrm{D}-\mathrm{L} / \mathrm{P}$ ratio. An angiography performed some days later showed complete occlusion of the right anterior cerebral artery. The $\mathrm{D}-\mathrm{L} / \mathrm{P}$ ratio continued to increase and reached sharp peak concentrations between 92 and 104 hours, then decreased significantly during the subsequent hours towards the normal ratio of 15-20. In conjunction with the increase in $\mathrm{D}-\mathrm{L} / \mathrm{P}$ ratio after aneurysm repair a pronounced increase in the D-glycerol concentration was found (fig 1). The peak D-glycerol concentration, about 15-fold the preoperative value, occurred 24 hours later. D-glycerol then slowly levelled off towards the preoperative concentration. A few smaller peaks were found during this normalisation phase. These chemical changes corresponded in time to the development of a cerebral infarct within the probe area in the right anterior cerebral artery territory. The diagnosis of infarct development during microdialysis was established by repeated CT and PET. $^{14}{ }^{15}$ The patient was assessed as severely disabled (GOS) at three month follow up.

CASE 2

This patient (a 69 year old man) developed severe systemic hypoxaemia and multiple hypodense lesions in the brain, including the frontal lobe harbouring the probe, but not in the probe area. The patient had a subarachnoid haemorrhage with abrupt onset of unconsciousness. $\mathrm{He}$ was intubated and 


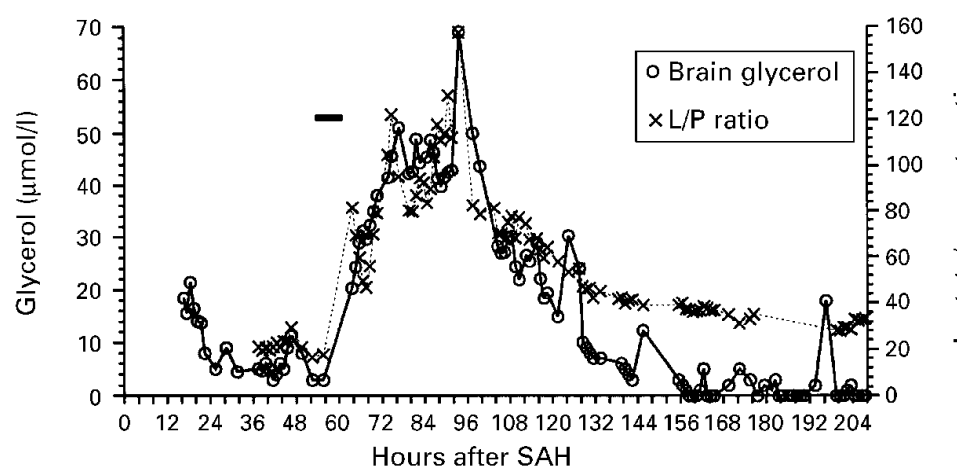

Figure 1 Microdialysate concentrations of glycerol and the lactate/pyruvate ratio in case 1; this patient with subarachnoid haemorrhage developed severe secondary ischaemia after aneurysm repair (denoted by horizontal bar) which resulted in a cerebral infarction in the microdialysis probe area.

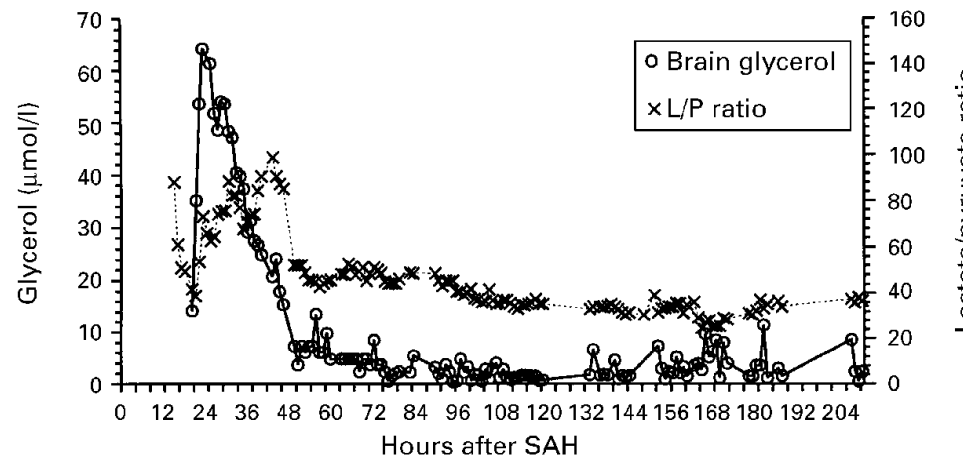

Figure 2 Microdialysate concentrations of glycerol and the lactate/pyruvate ratio in case 2; this patient with subarachnoid haemorrhage developed secondary hypoxia or ischaemia which resulted in multiple hypodense lesions remote from the microdialyisis probe area.

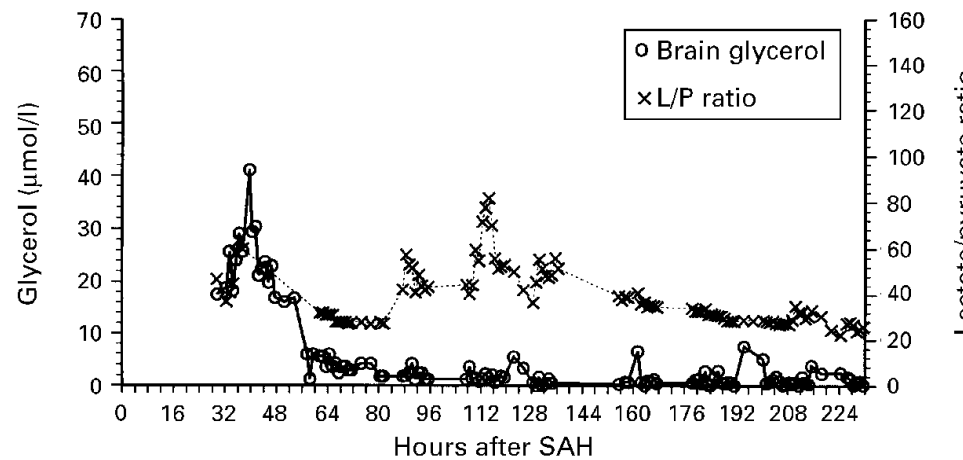

Figure 3 Microdialysate concentrations of glycerol and the lactate/pyruvate ratio in case 3; this patient with subarachnoid haemorrhage developed a cerebral infarct in the vicinity of the microdialyisis probe.
$\mathrm{D}-\mathrm{L} / \mathrm{P}$ ratio remained somewhat above the normal concentration. Also, in this patient a pronounced increase in D-glycerol was found in association with the increase of the $\mathrm{D}-\mathrm{L} / \mathrm{P}$ ratio during the first 48 hours. The peak concentration of D-glycerol was $65 \mu \mathrm{mol} / 1$, which was close to the peak value for case 1 . D-glycerol then gradually decreased to the low concentration seen initially in case 1 (below 10 $\mu \mathrm{mol} / \mathrm{l})$. During the final part of the observation period small D-glycerol peaks were occasionally seen but the concentrations never exceeded $15 \mu \mathrm{mol} / 1$. Several CT scans showed multiple hypodense lesions but failed to disclose any ischaemic lesion in the probe area (although a small hypodense lesion was seen in the white matter of the right frontal lobe). At the three month follow up the outcome was severe disability due to memory disturbances and confusion. He was ambulatory and had no motor deficits.

CASE 3

This patient (a 71 year old woman) also illustrated microdialysis findings in the frontal cortex in the vicinity of a cerebral infarct. The patient was admitted in Hunt and Hess grade III. The D-L/P ratios in the initial samples were moderately increased compared with estimated normal values and showed a peak about 36 hours after the subarachnoid haemorrhage(fig 3). In conjunction with this a moderate increase in D-glycerol was found. The peak concentration reached $40 \mu \mathrm{mol} / 1$ - that is, considerably less than in the first two cases. No particular clinical event could explain these early results. A secondary increase in $\mathrm{D}-\mathrm{L} / \mathrm{P}$ ratio occurred about 88 hours after subarachnoid haemorrhage and continued for about two and a half days. During this period the D-glycerol remained low. Brain CT after three months showed bilateral hypodensities in both frontal lobes close to, but not within the probe area. The cause of these infarcts could not be established. A second angiography performed during the second week after subarachnoid haemorrhage did not disclose arterial narrowing but despite this finding, clinical vasospasm seems to be the most plausible explanation. The patient was assessed as moderately disabled (GOS) at three month follow up.

ventilated and referred to us. On admission he had regained consciousness and was assessed as Hunt and Hess grade II and the CT was graded as Fisher 2. The medical history disclosed congestive heart disease and pulmonary emphysema and he was a heavy smoker. The microdialyisis probe was inserted with a ventricular catheter in conjunction with the aneurysm surgery. He was extubated directly postoperatively, but later developed respiratory problems with hypoxaemia and he deteriorated neurologically with depressed consciousness. He was reintubated and artificially ventilated. During the initial 48 hour period microdialyisis showed a pronounced temporary increase in $\mathrm{D}-\mathrm{L} / \mathrm{P}$ ratio, suggesting moderate to severe hypoxia/ischaemia (fig 2). During the rest of the observation period the
CASE 4

This patient (a 67 year old woman) was operated on for a right internal carotid aneurysm and showed an uneventful clinical course and a good recovery. The patient was graded as Hunt and Hess II on admission and CT was graded as Fisher 4. She received an intraventricular drainage for intracranial pressure monitoring. Several CT scans failed to demonstrate any structural changes in the frontal lobe harbouring the probe. The D-L/P ratio was initially normal, giving way to a slightly increased concentration during the remaining observation period (fig 4). Apart from the moderate increase during the first eight hours, D-glycerol remained at a low concentration (mostly below $10 \mu \mathrm{mol} / \mathrm{l}$ ) during the remaining microdialyisis period. 


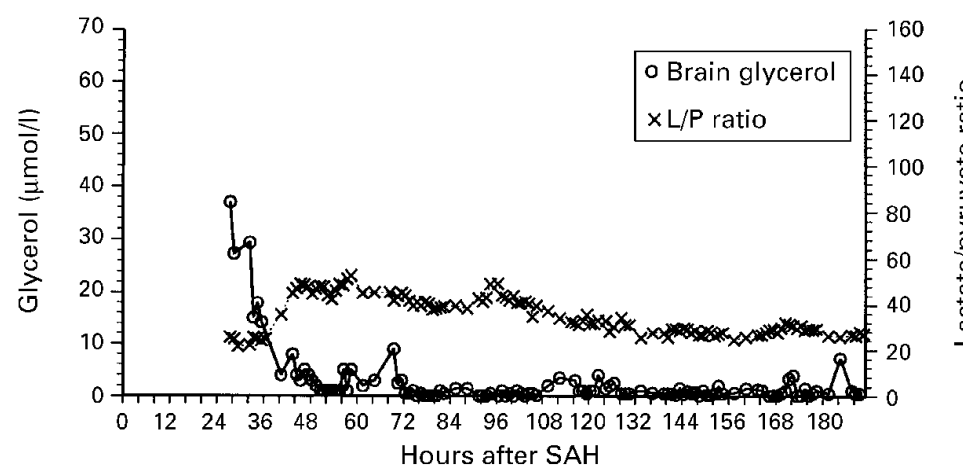

Figure 4 Microdialysate concentrations of glycerol and the lactate/pyruvate ratio in case 4; this patient with subarachnoid haemorrhage had an uneventful postoperative course and developed no signs of secondary ischaemia or structural brain damage in the frontal lobe harbouring the microdialyisis probe.

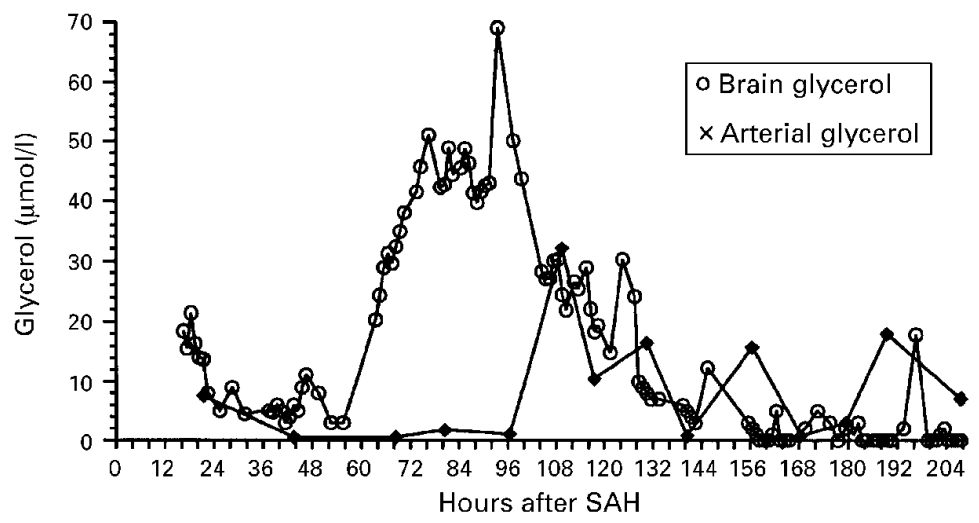

Figure 5 Glycerol changes in microdialysis samples from brain cortex and arterial plasma (case 1).

PLASMA GLYCEROL CONCENTRATIONS

Analysis of glycerol concentrations in microdialysates from arterial plasma samples, using the same microdialysis conditions as for the brain, showed that arterial plasma D-glycerol concentrations were generally lower than brain D-glycerol concentrations and thus there was no indication that increases in brain glycerol were preceeded by an increase in arterial glycerol. Figure 5 illustrates brain and arterial $\mathrm{D}$-glycerol in case 1 . The data demonstrate that the increase of brain D-glycerol occurred before and was larger than for arterial D-glycerol. Similar findings were made for the other three patients (data not shown).

\section{STATISTICS}

The results from the simple regression analyses showed a strong positive correlation between brain $\mathrm{D}$-glycerol and $\mathrm{D}-\mathrm{L} / \mathrm{P}$ ratio $\left(R^{2}=0.57\right)$. A similar correlation appeared between D-glycerol and D-hypoxanthine $\left(R^{2}=0.80\right)$. There was a weak correlation between D-glycerol and D-glutamate $\left(R^{2}=0.17\right)$ and D-lactate $\left(R^{2}=0.08\right)$, respectively.

\section{Discussion}

after the original works of Bazan $^{12}$ the phenomenon of membrane phospholipid degradation has been extensively studied, particularly in experimental models of cerebral ischaemia, hypoxia, hypoglycaemia, and epilepsy, but also in CNS trauma (for reviews $\mathrm{see}^{452425}$ ). To our knowledge the present study is the first to show increased interstitial glycerol concentrations, suggesting increased membrane phospholipid degradation in acute brain injury in humans. Clinical events involving secondary cerebral hypoxia/ischaemia after subarachnoid hemorrhage, as evidenced by, for example, greatly increased dialysate (D)-L/P ratios and neuroimaging findings, were generally associated with robust increases (up to 15-fold) of brain D-glycerol. Our results suggest that interstitial glycerol may be a valuable marker for monitoring of membrane phospholipid degradation in acute human brain injury and a useful surrogate end point for evaluation of neuroprotective therapies.

\section{GENERAL QUESTIONS}

Before discussing the individual patient data a few general questions are considered. Firstly, what does an increase in brain interstitial glycerol mean? Although little is known about normal interstitial glycerol concentrations in the brain there may be a blood to brain gradient for glycerol. ${ }^{17}$ Furthermore, systemic glycerol concentrations are known to increase in response to stress-for example, by cathecolamine induced lipolysis in adipose tissue. ${ }^{26}$ Therefore, an increased interstitial glycerol concentration in acute brain injury could reflect leakage of glycerol over a disrupted blood-brain barrier. The simultaneous measurement of arterial plasma glycerol in this study showed, however, that the changes in brain glycerol could not be attributed to a systemic overflow via a damaged blood-brain barrier, supporting the view that these were primarily intracerebral events. Previous experimental work on cerebral ischaemia has shown a substantial increase (4-fold15-fold) of brain tissue glycerol..$^{7-9}$ Those authors concluded that the increase in glycerol reflected membrane phospholipid breakdown as glycerol is an end product of membrane phospholipid hydrolysis and as other possible sources were not likely. Thus triglycerides are only found in trace amounts in brain tissue ${ }^{27} 28$ and during ischaemia carbohydrate stores are quantitatively transformed into lactate. ${ }^{29} \mathrm{Al}-$ though the transport mechanisms of glycerol between the extracellular and intracellular compartments are not known, we assume that the increases of interstitial glycerol found in this study reflect the same phenomenon as in experimental brain ischaemia - that is, membrane phospholipid degradation. Secondly, what are the triggering mechanisms for membrane phospholipid degradation? Loss of $\mathrm{Ca}^{2+}$ homeostasis and energy failure are thought to be the main triggering events for membrane phospholipid degradation in cerebral ischaemia, ${ }^{424}$ but a free radical mediated mechanism may also be involved. ${ }^{33031}$ It is noteworthy that energy failure is not a prerequisite as seizures with a relatively well preserved energy state were associated with accumulation of free fatty acids ${ }^{32}$ and glycerol. ${ }^{8}$ In this situation receptor mediated phospholipase activation may be the predominant factor, triggered by, for example, excitatory amino acids. ${ }^{25} 3334$ Thirdly, what does increased membrane phospholipid degradation mean? It is generally 
thought that in acute brain injury it is an important pathophysiological event underlying the disturbance of vital cellular membrane functions. Whether or not membrane phospholipid degradation reflects irreversible brain damage is not clear. ${ }^{4}$ Because membrane phospholipid degradation can occur under certain conditions (hypoglycemic coma) without detectable brain damage this is not necessarily the case. Therefore, normalisation of brain interstitial glycerol concentrations may reflect either recovering or dying cells (see below).

INDIVIDUAL PATIENT DATA

The patients with subarachnoid haemorrhage in this study were selected because they showed secondary cererebral hypoxia/ischaemia of varying severity. Thus case 1 had a long lasting episode of secondary ischaemia leading to cerebral infarction in the microdialyisis probe area, cases 2 and 3 temporary secondary hypoxia/ischaemia without infarction in the probe area, and case 4 minor disturbances of energy metabolism and no structural changes in the frontal lobe harbouring the microdialyisis probe. The ischaemic event in case 1 was associated with a pronounced increase of D-glycerol. This probably reflected profound ischaemia with energy failure as the $\mathrm{D}-\mathrm{L} / \mathrm{P}$ ratio rise was large and accompanied by an undetectable $\mathrm{D}$-glucose concentration and increased D-hypoxanthine and D-glutamate. ${ }^{15}$ This was supported by the occlusion of the right anterior cerebral artery diagnosed by a second angiography and the infarct development in the microdialyisis probe area according to CT and PET. ${ }^{15}$ In view of these findings the normalisation of D-glycerol starting 96 hours after subarachnoid haemorrhage most likely reflected dying cells and diffusion of glycerol to surrounding tissue rather than recovery from ischaemia. Notably, the increase in $\mathrm{D}-\mathrm{L} / \mathrm{P}$ ratio and D-glycerol concentration occurred concomitantly. This is consistent with previous experimental studies showing a good correlation between increases of glycerol in brain homogenate and energy failure during experimental cerebral ischaemia. ${ }^{8}$ The early event in case 2 was also associated with a pronounced but more transient increase in D-glycerol. Although the increased D-L/P ratio was somewhat less pronounced than in case 1 this was probably an episode of severe temporary hypoxia/ischaemia with energy failure as both D-hypoxanthine and D-glutamate concentrations were high. ${ }^{15}$ There was no conspicuous clinical explanation for this event. The lack of structural changes in the probe area on CT suggests that the normalisation of D-glycerol (and the other microdialyisis indices) reflected recovery of cell metabolism in this situation. Case 3 showed two episodes of moderately increased $\mathrm{D}-\mathrm{L} / \mathrm{P}$ ratio, one early and the second one starting 88 hours after subarachnoid haemorrhage. Both events featured preserved D-glucose concentrations and mild to moderate increases in D-hypoxanthine and D-glutamate, ${ }^{15}$ suggesting partial ischaemia. The early ischaemic episode was associated with a moderate increase of D-glycerol whereas the second episode was not. The reason for this is not known, but a significantly higher D-hypoxanthine concentration ${ }^{15}$ suggests a more pronounced energy disturbance during the early event. Case 4 showed an uneventful clinical course and a good recovery. She displayed no structural brain damage and seemed to have close to normal energy metabolism (D-L/P ratio only slightly above normal). In general, this was associated with a low concentration of D-glycerol, similar to the concentration seen in the other patients under presumed non-ischaemic conditions. The initial moderate increase of D-glycerol was associated with a dramatic increase in D-hypoxanthine and D-glutamate but no other signs of ischaemia. ${ }^{15}$ This phenomenon has been noted in several patients with subarachnoid haemorrhage and could reflect recovery from the global ischaemia produced by the aneurysm rupture, as discussed elsewhere. ${ }^{13} 15$ The high initial D-glutamate is probably a sufficient explanation for the early increase in D-glycerol. Although case 4 was chosen as a "control patient", it should be noted that a brain subjected to serious subarachnoid haemorrhage, which is an ethical requirement for an invasive technique such as microdialyisis, cannot be expected to present perfectly normal conditions. It is therefore difficult at this stage to determine if the basal concentration in our patients under non-ischaemic conditions reflects a normal interstitial glycerol concentration or not. There is virtually no information available on interstitial glycerol concentrations in normal brain, as most previous studies measured glycerol in brain homogenates. ${ }^{7-9} \mathrm{We}$ found one study reporting a basal dialysate glycerol concentration of $2 \mu \mathrm{mol} / 1$ in rat brain, using a similar but not identical ( $3 \mathrm{~mm}$ membrane length instead of $4 \mathrm{~mm}$ ) microdialysis system. ${ }^{11}$

OVERALL RESULTS

A strong positive correlation was found between brain $\mathrm{D}$-glycerol and $\mathrm{D}-\mathrm{L} / \mathrm{P}$ ratio. The correlations between D-glycerol and D-glutamate or D-lactate were weak. This is in line with our previous finding that $\mathrm{D}-\mathrm{L} / \mathrm{P}$ ratio had a high specificity as a marker for ischaemia, as defined by PET criteria, whereas the specificity for D-glutamate and D-lactate was low. ${ }^{14}$ Hypoxanthine, another commonly used marker for energy metabolic perturbations, also showed a strong positive correlation with glycerol. These findings support the concept from previous experimental work that membrane phospholipid degradation measured as glycerol accumulation is strongly correlated with ischaemia or trauma with a perturbed energy state. ${ }^{8-11}$

\section{Conclusions}

This study provides data suggesting that membrane phospholipid degradation occurs in human cerebral ischaemia. Clinical events involving secondary hypoxia/ischaemia after aneurysmal subarachnoid haemorrhage were generally associated with large increases of interstitial glycerol. Interstitial brain glycerol 
harvested by microdialysis seems to be a promising new tool for monitoring of lipolytic activity in acute brain injury. The marker may be useful for studies of injury mechanisms related for example, to distubed $\mathrm{Ca}^{2+}$ homeostasis, excitotoxicity, and reactive oxygen species, as well as in the evaluation of new neuroprotective therapeutic strategies.

We thank Ms Ulla Karlsson and Ms Lena Nalmo for skilful technical assistance. This study was supported by the Swedish Medical Research Council (project no 7888), The 1987 Foundation for Stroke Research, The Upjohn Company, CMA Microdialysis AB, Selander's Foundation, The Laerdal Foundation for Acute Medicine, The Åhlén Foundation, and King Gustaf V and Queen Victoria's Foundation.

1 Bazan NG. Effects of ischemia and electroconvulsive shock on free fatty acid pool in the brain. Biochem Biophys Acta 1970;218:1-10.

2 Bazan NG. Changes in free fatty acids of brain by drug-induced convulsions, electroshock and anesthesia. $\mathcal{F}$ Neurochem 1971;18:1379-85.

3 Chan PH, Yurko M, Fishman RA. Phospholipid degradation and cellular edema induced by free radicals in brain tion and cellular edema induced by free ra 4 Siesjö BK, Katsura K. Ishemic brain damage: focus on lipid
mediators. In: Bazan N, Toffano G, Murphy M, eds. Neumediators. In: Bazan N, Toffano G, Murphy M, eds. Neu-
robiology of essential fatty acids. New York: Plenum press, robiology of esser

5 Anderson DK, Hall ED. Lipid hydrolysis and free radical formationin central nervous system trauma. In: Salzman S $\mathrm{K}$, Faden A I, eds. The neurobiology of central nervous system trauma. New York: Oxford University Press, 1994:131-8.

6 Lynch DR, Dawson TM. Secondary mechanisms in neuronal trauma. Curr Opin Neurol 1994;7:510-6.

7 Gercken G, Bräuning C. Quantitative determination of hydrolysis products of phospholipids in the ischaemic rat brain. Pflügers Arch 1973;344:207-15.

8 PaschenW, van den Kerckhoff W, Hossmann K-A. Glycerol as an indicator of lipid degradation in bicuculline-induced seizures and experimental cerebral ishemia. Metab Brain Dis $1986 ; 1: 37-44$.

9 Bertrand N, Ishii H, Spatz M. Regional and temporal glycerol changes induced by forebrain ishemia in gerbils. Neuerol changes induced by
rosci Lett 1992;148:81-4.

10 Marklund N, Salci K, Lewén A, et al. Extracellular glycerol as a marker for membrane phospholipid degradation in traumatic brain injury. $\mathcal{F}$ Neurouma 1996;13:600.

11 Marklund S, Salci K, Lewén A, et al. Glycerol as a marker for post-traumatic membrane phospholipid degradation in rat brain. Neuroreport 1997;8:1457-61.

12 Hillered L, Persson L, Pontén U, et al. Neurometabolic monitoring of the ischaemic human brain using microdialysis. Acta Neurochir (Wien) 1990;102:91-7.

13 Persson L, Hillered L. Chemical monitoring of neurosurgi$\mathrm{cal}$ intensive care patients using intracerebral microdialysis. f Neurosurg 1992;76:72-80.

14 Enblad P, Valtysson J, Andersson J, et al. Simultaneous intracerebral microdialysis and positron emission tomogra- phy in the detection of ischemia in patients with subarachnoid hemorrhage. 7 Cereb Blood Flow Metab 1996;16:63744.

15 Persson L, Valtysson J, Enblad P, et al. Neurochemical monitoring using intracerebral microdialysis in patients with subarachnoid hemorrhage. $\mathcal{F}$ Neurosurg 1996;84:60616

16 Hillered L, Valtysson J, Enblad P, et al. Extracellular glycerol as a marker of membrane lipid degradation in the acutely injured human brain. Society for Neurosciences 1996;22: 1898

17 Foster KJ, Alberti KG, Hinks L, et al. Blood intermediary metabolite and insulin concentrations after an overnight fast: reference ranges for adults, and interrelations. Clin Chem 1978;24:1568-72.

18 Hallström A, Carlsson A, Hillered L, et al. Simultaneous determination of lactate, pyruvate, and ascorbate in microdialysis samples from rat brain, blood, fat, and muscle using high-performance liquid chromatography. 7 Pharmacol Methods 1989;22:113-24.

19 Persson L, Hillered L. Intracerebral microdialysis. 7 Neurosurg 1997;85:984-5.

20 Benveniste H. Brain microdialysis. F Neurochem 1989;52: 1667-79.

21 Jennett B, Bond M. Assessment of outcome after severe brain damage. A practical scale. Lancet 1975; i:480-4.

22 Hunt WE, Hess RM. Surgical risk as related to time of intervention in the repair of intracranial aneurysms. $\mathcal{F} \mathrm{Neu}$ rosurg 1968;28:14-20.

23 Fisher CM, Kistler JP, Davis JM. Relation of cerebral vasospasm to subarachnoid hemorrhage visualized by computerized tomography scanning. Neurosurgery 1980;6:1-9.

24 Wieloch T Siesjö BK. Ischemic brain injury: the importance of calcium, lipolytic activities and free fatty acids. Pathol Biol (Paris) 1982;30:269-77.

25 Farooqui AA, Horrocks LA. Excitotoxicity and neurological disorders: involvement of membrane phospholipids. Int Rev Neurobiol 1994:36:267-323.

26 Felländer G, Nordenström J, Tjäder I, et al. Lipolysis during abdominal surgery. F Clin Endocrinol Metab 1994;78:150-5.

27 Rowe CE. The measurement of triglycerides in brain and the metabolism of brain triglycerides in vivo. $\mathcal{F}$ Neurochem 1969;16:205-14.

28 Agranoff BW, Haira AK. Lipids in basic neurochemistry: molecular, cellular, and medical aspects. In: Siegel G J, ed. Basic neurochemistry. New York: Raven Press, 1994:97-112.

29 Gercken G, Preuss $H$. The effect of breathing oxygen on the metabolism of the rat brain under normal and ishemic conditions. F Neurochem 1969;16:761-7.

30 Chan PH, Fishman RA. The role of arachidonic acid in vasogenic brain edema. Fed Proc 1984;43:210-3.

31 Lewén A, Salci K, Marklund N, Hillered L. The spin trap PBN reduces extracellular glycerol and lactate levels following traumatic brain injury in rats. $f$ Neurotrauma 1996;13:600.

32 Siesjö BK, Agardh C-D, Bengtsson F, et al. Arachidonic acid metabolism in seizures. Ann NY Acad Sci 1989;559:32339

33 Nicoletti F, Meek JL, Iadarola MJ, et al. Coupling of inositolphospholipid metabolism with excitatory amino acid recognition sites in rat hippocampus. $\mathcal{F}$ Neurochem 1986;46: 40-6.

34 Ronne-Engström E, Hillered L, Flink R, et al. Intracerebral microdialysis of extracellular amino acids in the human epileptic focus. $\mathcal{F}$ Cereb Blood Flow Metab 1992;12:873-6. 